\title{
Incidencia de las políticas familiares en el empleo femenino en los estados de bienestar del sur de Europa en perspectiva comparada ${ }^{*}$
}

\author{
Almudena Moreno Mínguez \\ Universidad de Valladolid. Departamento de Sociología y Trabajo Social \\ Plaza de Colmenares, s/n. 40001 Segovia \\ almudena@soc.uva.es
}

\section{Resumen}

El objetivo de este artículo es presentar los hallazgos más relevantes de una investigación comparada realizada sobre la incidencia que ha tenido el desarrollo de las políticas familiares desarrolladas por los diferentes estados de bienestar en el empleo femenino. La hipótesis de partida que ha guiado la realización de esta investigación se refiere al hecho de que, en los países del entorno del sur de Europa (España, Grecia e Italia), el limitado desarrollo institucional que han tenido las políticas familiares ha reducido la incorporación de la mujer al mercado laboral, lo que explicaría las reducidas tasas de actividad y ocupación femeninas características de estos países. Para llevar a cabo la investigación, se ha empleado la perspectiva comparada y la explotación de datos procedentes de diferentes fuentes estadísticas, tales como Eurostat y la OCDE.

Palabras clave: políticas familiares, empleo femenino, estados de bienestar, familia.

\section{Abstract. Incidence of the family policies on the female employment in the Southern European Welfare States from a compared perspective}

The aim of this paper is to present the main achievements from a research in compared perspective carried out on the incidence that the development of the family policies in different Welfare States have had in the female employment. The hypothesis as starting point that has guided this research refers to the fact that in the Southern European countries (Spain, Greece and Italy) the scarce institutional development in the family policies has limited the incorporation of the women to the labour market, what would explain the reduced female activity rates and female employment that characterize these countries. To carry out the research it has been used the compared perspective and the exploitation of the different statistical data sources such as Eurostat and the OECD.

Key words: family policies, female employment, welfare states, family.

* Deseo expresar mi gratitud a los evaluadores externos, así como agradecer los comentarios de todos y cada uno de los compañeros amigos que me han alentado en la redacción de este trabajo. 


\section{Sumario}

Familias y estados de bienestar en el sur de Europa en perspectiva comparada Políticas familiares y empleo de la mujer en los estados de bienestar del sur de Europa
Incidencia de las políticas familiares en el empleo femenino

Conclusiones

Bibliografía

\section{Familias y estados de bienestar en el sur de Europa en perspectiva comparada}

Las directrices históricas que han marcado el desarrollo de las políticas familiares en Europa se han construido sobre la base de modelos de estados de bienestar históricamente determinados. Desde que Titmus publicara el primer ensayo sobre el estado de bienestar en 1958, se ha producido una amplia literatura, tanto sobre el proceso histórico de formación, como sobre las funciones de los estados de bienestar.

El tradicional estado de bienestar keynesiano tenía como objetivo básico el mantenimiento de las rentas del trabajador asalariado (generalmente, varón), por lo que se daba por supuesto que la familia debía ser funcional a los intereses del estado capitalista. En este sentido, los trabajos de Gauthier (1996; 1999; 2003) han tratado de reconstruir la historia de las políticas familiares a través de la lectura e identificación de los programas y de las medidas que se fueron introduciendo con distinta periodicidad e intensidad en los distintos estados europeos tras la finalización de la Segunda Guerra Mundial. La lectura de estos trabajos constata que los programas estaban dirigidos, en su mayoría, a la población asalariada, es decir, a los trabajadores varones.

Del análisis de las primeras medidas que se aplican en materia de política social y familiar, se desprende la importancia que cada estado ha concedido en cada momento histórico a la familia, como institución objeto de derechos universales o como institución objeto de derechos individualizados, lo cual es también ejemplificador de la intelección que los diferentes estados han hecho de las funciones y las relaciones familiares en cada momento histórico.

En los análisis teóricos realizados para tipologizar a los estados de bienestar, destaca una tendencia analítica que han utilizado buena parte de los investigadores de las políticas sociales, que es la de considerar de forma aislada la producción de bienestar por parte de las instituciones estatales. Tal y como ha señalado Moreno (2002b: 7), se trata de una perspectiva reduccionista que no suele considerar la actuación interdependiente de los tres grandes productores de bienestar: el estado, el mercado (laboral principalmente) y la familia. El hecho de no incluir a la familia, dadas las dificultades de obtención de datos que ello comporta, ha dificultado la compresión de los grados reales de satisfacción vital de los ciudadanos (well-being) en las democracias de bienestar social (welfare democracies). Según esto, resulta más pertinente referirse a una categoría analítica más amplia, como la de «régimen de bienestar», la cual permi- 
te introducir, de forma dinámica e interdependiente, a los tres principales productores de bienestar: estado, mercado y familia.

Según el enfoque teórico referido a los regímenes de bienestar (welfare regime approach $)^{1}$, el complejo juego de interrelaciones que mantienen economía, familia y estado se refleja en la gestión de diferentes políticas sociales y familiares. De hecho, las directrices de política familiar están estrechamente vinculadas con los modelos de estado de bienestar que se han ido consolidando históricamente en Occidente. Tal y como se ha plasmado en la literatura científica, son numerosas las tipificaciones existentes sobre los estados de bienestar. Destacan, entre otras, la clasificación de Castles (1993), quien, desde una perspectiva histórica y cultural, se refiere a las «familias de naciones» y las tipologías elaboradas por Lewis (1992), Sainsbury (1999) o Trifiletti (1999), quienes se refieren a los «regímenes de género», pero quizás la propuesta de tipificación que más envergadura y más repercusión ha tenido haya sido la de Esping Andersen (1993; 2000), elaborada a partir de la categoría de «regímenes de bienestar». El paradigma analítico de los «regímenes de bienestar» ha permitido a Esping Andersen teorizar sobre los tres modelos del bienestar capitalista, según los cuales la acción del estado es la variable independiente clave en la producción del bienestar. Según esta perspectiva, las estructuras estatales disponen de una relativa autonomía que las hace responsables del desarrollo de los sistemas sociales de provisión social. En estos parámetros analíticos, el autor ha tratado de perfilar tres modelos de actuación de los estados de bienestar, utilizando los indicadores de producción de bienestar y reparto de responsabilidades familiares entre familia, estado y mercado. Para ello, ha tratado de analizar el nexo existente entre familia, mercado y estado utilizando la categoría analítica referida al proceso de «desfamiliarización», proceso ligado a la individualización y a la producción de bienestar. De esta forma, Esping Andersen, en un intento de síntesis comparativa, propone distinguir tres regímenes de estado de bienestar a partir de las diferencias observadas en la estratificación social del bienestar y en las relaciones entre estado, mercado y familia (régimen socialdemócrata, conservador y liberal). Para ello, introduce la variable familiar, que hasta estos momentos había estado prácticamente ausente de los estudios macroeconómicos sobre los estados de bienestar.

La familia ocupa un lugar prioritario en las tipologías definidas por Esping Andersen. De hecho, distingue tres tipos de estado de bienestar en función del grado de familiarismo ${ }^{2}$ y desfamiliarización presente en cada uno de ellos. En

1. El título original del libro de Esping Andersen, publicado en 1990, The Three Worlds of Welfare Capitalism, hace referencia a las economías de mercado de las democracias occidentales en los términos utilizados por T. H. Marshall respecto al capitalismo democrático del bienestar.

2. Esping Andersen utiliza el término familiarismo para referirse al estado de bienestar que asigna a la unidad familiar la máxima responsabilidad en la producción de bienestar. El término desfamiliarización está íntimamente relacionado con el concepto de familiarismo, ya que ambos se refieren a diferentes grados de dependencia familiar. En concreto Esping Andersen entiende por desfamiliarización «el proceso mediante el cual las políticas 
el régimen de bienestar liberal, los servicios familiares son considerados como una actividad propia del mercado y, por tanto, como una responsabilidad individual. En estos regímenes, existe una política de empleo activa que posibilita la incorporación de la mujer al mercado de trabajo y, por tanto, la externalización de los servicios familiares, aunque las prestaciones familiares se realizan a través del mercado. En lo que respecta al régimen de bienestar conservador, éste se caracteriza, fundamentalmente, por la asistencialización y privatización de los servicios familiares, que ha derivado en lo que Esping Andersen ha denominado familiarismo. Participan de esta tradición familiarista, según Esping Andersen, países tan diferentes como Austria, Alemania, Bélgica, Francia, Italia y España. A este respecto, hay que subrayar que este carácter familiarista ${ }^{3}$ se utiliza con diferentes connotaciones referidas a distintas situaciones familiares y políticas que, en muchos casos, no son comparables y, por lo tanto, difícilmente homogeneizables en un modelo o tipología. La clasificación realizada por Esping Andersen para referirse a los diferentes regímenes de bienestar se fundamenta en el grado en que las familias, los mercados de trabajo y los estados hacen frente a los riesgos sociales de las economías postindustriales. A partir de estas consideraciones, elabora el concepto de familiarismo para categorizar a los diferentes regímenes de bienestar. En esta tipología, las variables culturales y los valores parecen tener una clara relación con los factores estructurales, es decir, con la actuación de los estados y los mercados en materia de política familiar y de empleo (Fernández y Fogli, 2005). Desde mi punto de vista, es precisamente en este aspecto donde radica uno de los flancos débiles de la tipología elaborada por Esping Andersen, ya que su estudio referido al régimen de bienestar conservador no clarifica en qué medida los mercados y los estados han contribuido a conformar ese «ethos familiar» denominado familiarismo, es decir, no se profundiza adecuadamente en el análisis de cómo lo cultural, lo institucional y lo económico se relacionan dando forma a las estrategias familiares adoptadas por los ciudadanos. A la luz del trabajo de Esping Andersen, se han multiplicado los estudios comparados sobre el estado de bienestar, entre los que destacan aquellos que apuntan la existencia de un idiosincrásico «régimen de bienestar mediterráneo».

reducen la dependencia individual de la familia y que a su vez maximizan la disponibilidad de los recursos económicos por parte del individuo independientemente de las reciprocidades familiares o conyugales» (Esping Andersen, 2000: 66). En definitiva, por desfamiliarización se entiende el proceso mediante el cual los individuos han conseguido emanciparse de las dependencias familiares a través de la actuación de los estados y los mercados, en el sentido de individualización de los derechos de ciudadanía. Por el contrario, el término familiarismo hace referencia a estructuras normativas por las que se reproduce la dependencia familiar y la solidaridad entre los miembros de una familia (Zuanna, 2001; Saraceno, 1994). En ambos casos, la tasa de empleo femenino es un buen indicador para expresar el grado de desfamiliarización de una sociedad. Lesthaeghe (1986) ha utilizado el término familismo para referirse a los condicionantes demográficos, económicos y culturales que retrasaron la segunda transición demográfica en los países mediterráneos.

3. Messu (2000) utiliza el concepto de familialism con una significación muy diferente al familismo característico de España e Italia, entendido como solidaridad y dependencia familiar, para referirse a la ideología que ha impregnado a la política familiar en Francia. 
La tipología de Esping Andersen se ha convertido, en la literatura científica, en un referente obligado para realizar cualquier estudio comparado sobre el estado de bienestar. Sin embargo, en el caso del estudio que me ocupa, resulta un modelo válido pero insuficiente para explicar la reducida participación laboral de las mujeres en los países del sur de Europa, ya que, como han puesto de manifiesto autores como Ebbinghaus (1998) y Flaquer (2002), se observan numerosas diferencias interregionales dentro de un mismo régimen de bienestar. En el caso de los países mediterráneos (España, Italia y Grecia) se observan, por una parte, ciertas similitudes referidas al clientelismo y la subsidiariedad característicos de las políticas públicas (Ebbinghaus, 1998; Ferrera, 1996; Leibfried, 1993; Saraceno, 2003). Por otra parte, destaca también el reducido soporte público destinado a las familias con personas dependientes y, en concreto, a las madres trabajadoras (Daly y Rake, 2004; Gornick, 1997; Hantrais and Letablier, 1996; Trifiletti, 1999; Meulders y O’Dorchai, 2002). Otras similitudes encontradas se refieren a la trayectoria histórica marcada por la influencia de la religión católica y los regímenes dictatoriales (Castles, 1998; Naldini, 2003) y a la peculiar división del trabajo familiar según género ante el empleo (Korpi, 2000; Walby, 2001; Lewis y Ostner, 1994). Según estas interpretaciones, los estados de bienestar han desarrollado distintos modelos de políticas familiares que, en cierta medida, pueden haber tenido una incidencia dispar en el empleo de la mujer con cargas familiares. En otras palabras, el efecto de las políticas públicas sobre el empleo femenino ha sido y es, en cierta manera, indirecto y requiere la inclusión de variables específicas y una atención pormenorizada en el caso de los países del sur de Europa (España, Italia y Grecia), donde las tasas de actividad y ocupación femenina son comparativamente las más reducidas de la Europa de los quince.

En concordancia con este marco de análisis, autores como Ferrera (1996) Flaquer (2002), Moreno (2002), Naldini (2003) y Trifiletti (1999) consideran que, en cierto modo, es inapropiado incluir en la misma categoría de análisis a casos como Francia, Bélgica o Alemania, que cuentan con una larga tradición en la institucionalización de la política social y familiar, y a países como España, Italia y Grecia, donde existe un escaso desarrollo institucional de las políticas familiares. En concreto, Moreno (2002) se refiere al régimen de bienestar mediterráneo ${ }^{4}$ como un régimen con unos estilos de vida y unas necesidades de bienestar diferenciadas, en donde la familia se constituye como factor esencial de microsolidaridad complementaria de la acción estatal y de los servicios ofer-

4. El trabajo de Luís Moreno (2002) diferencia cuatro regímenes de bienestar (anglosajón, continental, nórdico y mediterráneo) a partir de la identificación de una serie de rasgos propios de cada régimen de bienestar referidos a la ideología, los objetivos, la financiación, los subsidios, los servicios, la provisión social, el mercado laboral, el género y la pobreza. El régimen de bienestar mediterráneo se caracteríza siguiendo el orden anterior de los rasgos señalados por la autonomía vital (ideología), por la combinación de recursos (objetivos), por la financiación mixta, por los subsidios contributivos, por los escasos servicios de apoyo familiar, por la provisión mixta y descentralizada, por un mercado laboral caracterizado por la economía informal, por el familismo ambivalente en cuanto al género y por la cultura asistencial en lo que se refiere a la pobreza. 
tados por las organizaciones privadas. Por tanto, el análisis comparado sobre los «regímenes y lógicas de bienestar» debe incluir, en el modelo analítico, variables referidas a la estructura del mercado laboral, al género y a las políticas familiares, variables que en cierta manera ayudan a explicar el escaso grado de desfamiliarización existente en los países del sur de Europa y, por tanto, la reducida participación laboral femenina que caracteriza a los países del sur de Europa en perspectiva comparada.

Los avances producidos en esta línea de investigación comparada sobre los estados del bienestar del sur de Europa han supuesto aportaciones de interés en el intento de explicar la reducida participación laboral de la mujer en función de las políticas públicas desarrolladas por estos estados. Así, Trifiletti (1999) apunta la existencia de un régimen de bienestar mediterráneo caracterizado por el familiarismo, en el que el estado considera a la familia como un ámbito privado en el que se han de resolver los conflictos familiares derivados de la compatibilización familiar y laboral. En este régimen de bienestar, el estado prácticamente no ha protegido a las familias de los riesgos derivados del mercado ni tampoco ha potenciado de forma activa la extensión de los derechos de ciudadanía a la mujer trabajadora. De esta forma, la estructura del mercado de trabajo, la escasa desfamiliarización potenciada por el estado y el mercado en materia de política familiar, así como las limitadas políticas de compatibilización laboral y familiar, propias del régimen de bienestar mediterráneo, han propiciado que la emancipación de la mujer se haya producido en el interior de la familia, lo que explica en parte que la participación laboral de la mujer sea tan reducida en estos países en comparación con la Europa de los quince (Bimbi, 1999; Bettio y Villa, 1993; 1998; Naldini, 2003).

\section{Políticas familiares y empleo de la mujer en los estados de bienestar del sur de Europa}

\section{La situación de las políticas familiares en perspectiva comparada}

Aunque pueda resultar paradójico, los avances en la democratización de la vida familiar han supuesto una progresiva intervención del estado y del mercado en un ámbito tradicionalmente consagrado a la privacidad como es la familia. La actuación de los gobiernos en el ámbito familiar se ha ido perfilando en los estados occidentales modernos a través de instrumentos de gestión y regulación como es la política familiar. En este sentido, es preciso subrayar que resulta difícil de compatibilizar la práctica de las políticas familiares con el mantenimiento de la privacidad en las relaciones familiares. Sin embargo, es cada vez más aceptado en todos los ámbitos sociales la necesidad de gestionar políticas familiares encaminadas a potenciar la individualización de los derechos familiares y, por tanto, el advenimiento de la familia democrática, aún más en un contexto en el que los indicadores demográficos tales como la fecundidad y el envejecimiento de la población pueden desestabilizar los pilares socioeconómicos básicos sobre los que se asentaron históricamente los modernos estados de bienestar. 
La individualización de la vida familiar ha potenciado la intervención activa del estado y el mercado en la vida familiar, con el objetivo último de garantizar la plena integración de los miembros de la familia en la vida pública y neutralizar así las dependencias familiares. Dadas las funciones y características de la familia, la cual sigue siendo considerada como uno de los principales ámbitos de socialización, y dado el arraigo de la familia en el imaginario social colectivo, resulta en cierta manera problemático plantear el tema de las políticas familiares sin dar entrada a debates ideológicos sobre la conveniencia, la función y la repercusión de las mismas. En cualquier caso, lo que sí parece cierto es que, desde la década de 1980, el estudio comparado de las políticas familiares cuenta con una sólida trayectoria investigadora que lo avala como una de las corrientes de investigación más reveladoras en sociología de la familia. Buen ejemplo de ello fue la creación, en 1989, del Observatorio Europeo de Políticas Familiares Nacionales, dependiente de la Comisión Europea.

Puesto que existen diversas y plurales concepciones de la política familiar en los distintos estados de bienestar vinculadas con principios ideológicos, políticos e incluso religiosos, es preciso definir qué entendemos por política familiar. Kamerman y Kahn (1978) han utilizado dos categorías para definir la política familiar: por un lado, se refieren a la política familiar explícita (incluirá todos aquellos programas y políticas especialmente diseñados para lograr determinados objetivos explícitos en relación con la familia) y, por otro, a la política familiar implícita (programas y políticas que, de forma deliberada, hacen algo a favor de la familia, pero sin que existan unos objetivos concretos referidos a la familia). Por su parte, Zimmerman (1988) conceptúa la política familiar como aquella que incorpora el bienestar familiar como criterio de planificación, es decir, que incorpora la perspectiva familiar al debate y a la gestión política, tanto en lo que se refiere a los objetivos como a la evaluación de resultados. Por su parte, Dumon califica de política familiar a «toda medida adoptada por el gobierno para mantener, sostener o cambiar la estructura y la vida familiar» (Dumon, 1987: 291).

Dado que no existe un concepto estándar ni unívoco de política familiar, en este trabajo he optado por acotar las dimensiones que abarca la misma a partir del concepto utilizado por autores como Iglesias de Ussel y Meil (2001) y Flaquer (2000), para quienes las políticas familiares integran el conjunto de medidas e instrumentos vinculados a las políticas sociales destinados a aportar recursos y servicios dirigidos a las personas con responsabilidades familiares, con el fin de que puedan desempeñar sus funciones familiares, sin que por ello se vean menoscabados sus intereses personales y sociales.

Esta definición de política familiar está directamente vinculada con la forma en que los distintos estados europeos entienden la protección a la familia y la infancia. En este punto, es pertinente subrayar que el ritmo y la dirección del cambio familiar en lo que se refiere al advenimiento de la familia postpatriarcal depende, en parte, de la naturaleza de la política familiar adoptada en cada estado nación. A este respecto, es preciso reseñar que las políticas familiares desarrolladas por los diferentes estados de bienestar han estado históricamen- 
te determinadas por aspectos ideológicos, institucionales y familiares sobre los que se han asentado los modernos estados de bienestar democráticos.

Por lo tanto, teniendo en cuenta el amplio abanico de dimensiones que integran la política familiar, a continuación se especifican los programas y las medidas de intervención en el ámbito familiar aplicados por los distintos estados. Es preciso subrayar que las metodologías y los criterios de actuación utilizados son muy diversos e incluyen desde la política de género y atención a la infancia hasta la protección social, económica y jurídica de la familia. En definitiva, las medidas de actuación en política familiar se pueden resumir en las siguientes ${ }^{5}$ :

\section{Componentes de la política familiar}

\section{Componentes tradicionales}

- Prestaciones económicas directas (por ejemplo: gastos en familia, ayudas para la vivienda, educación, becas, etc.).

- Prestaciones económicas indirectas (por ejemplo: desgravaciones fiscales y subsidios).

- Permisos de maternidad y parentales.

- Atención a la infancia.

\section{Componentes no tradicionales}

- Prestaciones económicas para el cuidado de ancianos (por ejemplo: gastos sociales destinados a la tercera edad).

- Pensiones contributivas para las personas con responsabilidades familiares.

- Políticas empresariales (flexibilización del tiempo de trabajo, compatibilización de horarios, teletrabajo, etc.).

\section{Derecho familiar}

- Legislación referida al matrimonio.

- Legislación referida al divorcio.

- Equiparación de derechos para las parejas cohabitantes.

- Legislación referida a los derechos y al bienestar del niño.

- Legislación referida al aborto, la contracepción y la inseminación.

- Legislación sobre abusos y violencia familiar.

- Legislación sobre delitos del menor.

\section{Servicios}

- Educación.

- Salud.

- Creación de centros de atención a niños y a madres maltratadas.

- Servicios familiares dirigidos a la infancia (por ejemplo: guarderías públicas).

\section{Otros servicios públicos}

- Política pública de transportes.

- Leyes de inmigración.

- Prestaciones por desempleo.

- Formación.

Fuente: elaborado a partir de los datos proporcionados por Gauthier (1999) y el Observatorio Europeo de Políticas Familiares.

5. Estas categorías han sido extraídas del Observatorio Europeo de Políticas Familiares. 
Esta amplia gama de medidas — a través de las cuales se gestionan las políticas familiares - evidencia la complejidad de la naturaleza de las políticas familiares, que abarcan prácticamente todos los ámbitos de las políticas públicas. Por esta razón, las políticas familiares durante mucho tiempo se han caracterizado por su ambigüedad y, en muchos casos, por la falta de contenido, como en el caso de los países mediterráneos. De hecho, tal y como ha señalado Flaquer (2002), la política familiar de los países pertenecientes al régimen familiar mediterráneo (fundamentalmente España e Italia) se define por la práctica ausencia de contenidos, financiación y debate público. En principio, este hecho parece constatar numerosas paradojas en unos países de fuerte tradición familiar como son España e Italia, donde la familia es la institución mejor valorada por los ciudadanos. Realmente, tras esta paradoja, se esconden contradicciones ideológicas que se han visto reflejadas en la gestión de las políticas familiares, cuyo fin último en las últimas décadas ha sido tratar de evitar el posible resurgir de las reminiscencias franquistas revividas a través de las políticas familiares. Esta práctica social y política se ha proyectado sobre el imaginario social colectivo de forma latente a través de los procesos de socialización, favoreciendo así la reproducción del modelo de familia tradicional patriarcal.

En cualquier caso, el ritmo de integración de la mujer en el mercado laboral ha estado vinculado, en parte, a la evolución de las políticas familiares adoptadas en cada estado de bienestar. En el caso de los países del sur de Europa, la limitada incorporación de la mujer al mercado laboral se vincula con el restrictivo tejido institucional de apoyo a las familias que han desarrollado estos estados de bienestar. En este sentido, son muy variadas las interpretaciones que han tratado de explicar el reducido empleo femenino que caracteriza a los países del entorno mediterráneo, aunque todas ellas apuntan, directa o indirectamente, a las dificultades que encuentran las mujeres para compatibilizar empleo y familia. Autores como Esping Andersen (1996; 2000) y, más concretamente, investigadores como Flaquer (2001), Ferrera (1996), Naldini (2002) o Del Boca (2002), Boeri, Del Boca y Pissarides (2005), entre otros, se refieren directamente a las políticas familiares como uno de los factores clave para explicar la reducida tasa de ocupación femenina de los países mediterráneos.

Por lo tanto, si partimos de la definición consensuada por los investigadores de que las políticas familiares se definen como políticas sociales de apoyo y atención a las familias con cargas familiares desarrolladas por los estados a través de diferentes instrumentos como las prestaciones económicas, los servicios familiares de atención a la infancia, las políticas de conciliación, las políticas fiscales, de vivienda, etc., entonces es preciso subrayar que la trayectoria histórica seguida por las políticas familiares en los diferentes países europeos puede haber tenido cierta incidencia en la vida familiar y, por tanto, en la reproducción y el empleo de la mujer. En el caso concreto de los países mediterráneos, el binomio de reducida fecundidad y reducido empleo femenino se explica, en parte, como una consecuencia de la limitada política familiar, la cual ha 
estado centrada históricamente en la figura del varón como principal sustentador económico de la familia. De hecho, las políticas familiares en el sur de Europa (fundamentalmente en España e Italia) se definen en función de criterios ideológicos arraigados en la historia política y social de estos países, lo que parece tener una clara vinculación con el clientelismo y el familiarismo, como algo característico de la historia social de las políticas sociales en estos países (Ferrera, 1996).

La convergencia de estas estrategias institucionales y familiaristas ha contribuido durante décadas a mantener a la familia como la principal institución encargada de la resolución de los problemas familiares, lo que ha limitado en cierta forma la emancipación familiar de la mujer y, por tanto, su integración en el mercado laboral.

\section{Situación laboral de la mujer en los paises del sur de Europa}

Si se analizan detenidamente los indicadores laborales femeninos para el año 2002 (tabla 1), se concluye que los países del sur de Europa (España, Grecia e Italia) tienen las tasas de actividad y ocupación femenina más reducidas de la Unión, así como las tasas de desempleo femenino más elevadas. En lo que se refiere a la estructura del mercado laboral, destaca el hecho de que estos países son los que menor porcentaje tienen de mujeres empleadas a tiempo parcial y en los que menor número de trabajadores emplea el sector servicios. Estos datos confirman el limitado acceso de la mujer al mercado laboral y apuntan a la existencia de factores externos, tales como el escaso desarrollo de las políticas familiares de compatibilización laboral y familiar, como uno de los factores fundamentales en la explicación del elevado desempleo femenino.

El desarrollo de las políticas familiares y de género en determinados países, como el caso de los pertenecientes al régimen de bienestar socialdemócrata, ha supuesto el desarrollo de servicios familiares de atención a la infancia y a la mujer, lo cual ha facilitado la compatibilización del trabajo familiar y profesional, además de potenciar la externalización de los servicios y, por tanto, el empleo de las mujeres en el sector servicios. De alguna manera, la activación de políticas familiares en estos países ha supuesto que la familia y en concreto los hijos, no sean un impedimento insalvable para que la mujer pueda emplearse en los distintos sectores del mercado de trabajo. Las fórmulas empleadas para favorecer la compatibilización familiar y profesional son muy variadas. En el caso concreto de los países mediterráneos, este problema se ha resuelto en parte mediante el desarrollo de estrategias privadas de actuación, tales como la «ayuda familiar» y la creación de «empresas familiares», en lugar de activar estrategias públicas de compatibilización laboral y familiar.

En este sentido, las estimaciones realizadas por Blanchet y Pennec (1993) para calcular el grado de incompatibilidad entre trabajo y familia a través del indicador denominado "coeficiente de incompatibilidad» para tres situaciones diferentes (mujer con dos hijos combinado con cualquier empleo, dos o más hijos combinado con cualquier empleo y dos o más hijos con un 
Tabla 1. Indicadores laborales femeninos (año 2003).

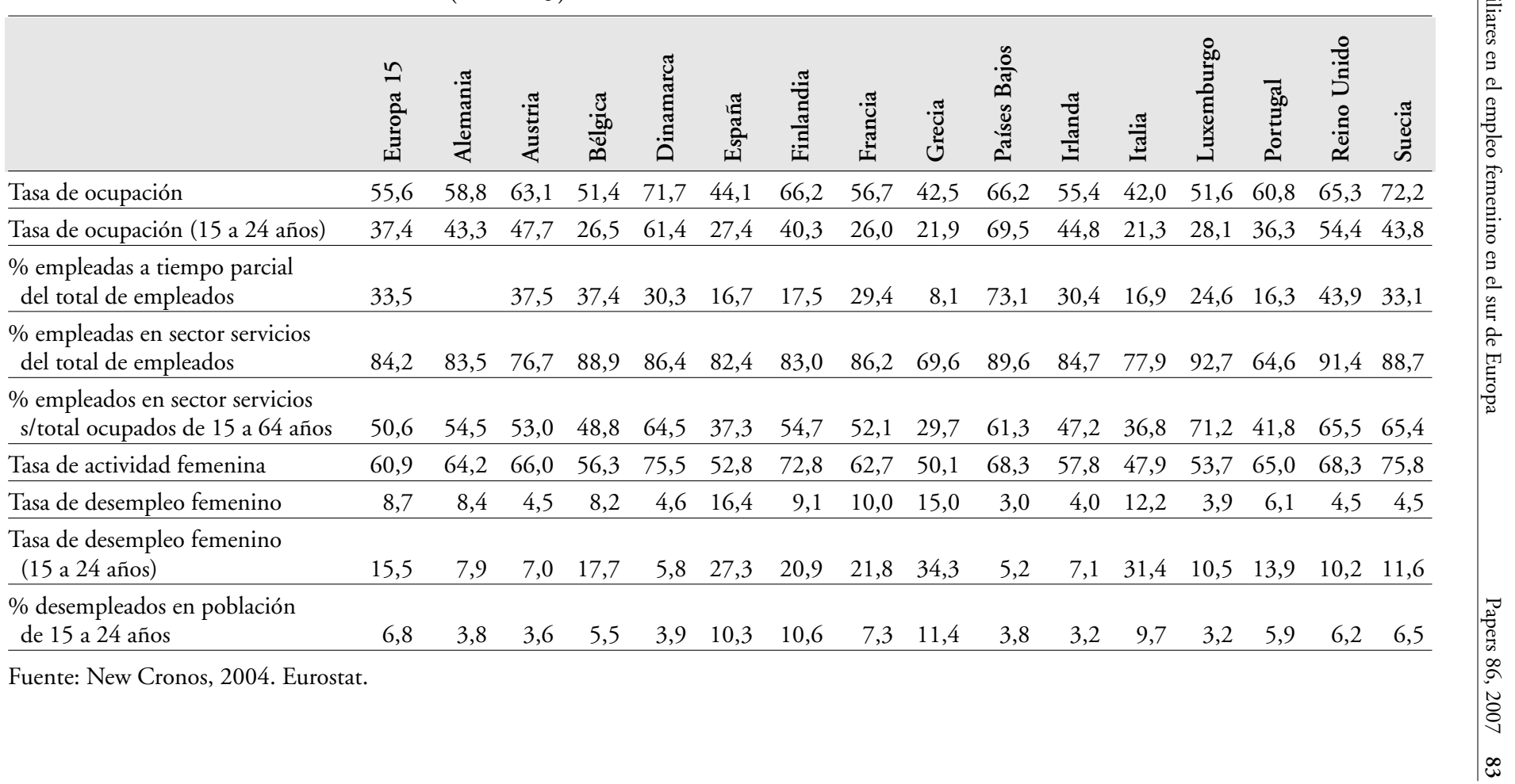


empleo a tiempo completo), resultan, desde mi punto de vista, escasamente clarificadoras, ya que, en el tercer caso, España, Portugal y Grecia obtienen la mejor puntuación en cuanto a compatibilización, mientras que Dinamarca se sitúa en la mitad, y Francia, los Países Bajos, Irlanda y Gran Bretaña presentan grados muy diferentes. Portugal es una excepción al modelo mediterráneo, porque tiene elevadas tasas de ocupación femenina, por lo que este indicador para el caso de España, Portugal, Grecia e Italia lo único que parece indicar es que, en estos países, nos encontramos con un importante potencial de autoempleo a través de las empresas familiares, que resultan ser un eficiente recurso para emplear a la mujer y resolver de forma privada los problemas de compatibilización laboral y familiar (Mingione, 1995; Bettio y Villa, 1998), pero este indicador sólo incluye a las mujeres que están trabajando y obvia a las que desean trabajar, por lo que no permite relacionar la actividad laboral de la mujer con el grado de compatibilización y los índices de fecundidad.

En lo que respecta al mercado laboral, las políticas laborales y salariales desarrolladas durante las décadas de los setenta y los ochenta en los países mediterráneos han contribuido a consolidar el trabajo a tiempo completo, fundamentalmente el del varón sustentador, lo cual limita, de esta forma, la creación de empleo flexible. Como consecuencia de ello, un gran número de mujeres casadas con hijos han tenido que elegir durante décadas entre trabajar a tiempo completo, lo cual no facilita la compatibilización laboral y familiar o el trabajo familiar. De hecho, como consecuencia de la rigidez del mercado laboral y la ausencia de una política explícita de ayuda a las familias con cargas familiares, la mujer ha visto dificultadas sus posibilidades de integrarse en el mercado laboral de forma óptima. En esta línea de investigación, los trabajos empíricos realizados por Del Boca (2002) para el caso italiano, y Boeri, Del Boca y Pissarides (2005), han evidenciado cómo la rigidez del mercado laboral y la carencia de ayudas familiares destinadas a las madres con hijos son variables claves a tener en cuenta para explicar la reducida participación laboral de la mujer en los países del sur de Europa.

Teniendo por tanto en cuenta estas consideraciones relativas a las características de la política familiar y a la política de empleo de los países mediterráneos, resulta posible explicar cómo el proceso de reducción de la fecundidad producido en estos países no ha estado acompañado de un aumento similar de la participación laboral de la mujer, o de lo que se ha denominado "proceso de desfamiliarización» similar al acontecido en los países del norte de Europa, ya que los países mediterráneos, con la excepción de Portugal, tienen las tasas de ocupación femenina más reducidas del continente, tanto en las mujeres sin hijos como en las mujeres con cargas familiares (ver tabla 2). La clave interpretativa de este enigma, tal y como se ha señalado previamente, se encuentra en el coste económico y laboral que suponen los hijos para las familias. Mientras que en determinados países (Noruega, Dinamarca, Suecia), el coste económico y el coste de oportunidad laboral que suponen los hijos para las familias y las mujeres es relativamente moderado, debido a la actuación de los estados 
y los mercados, que han puesto en práctica políticas familiares de conciliación y de ayuda a las familias con hijos, sin embargo en los países mediterráneos son las propias familias, a través de estrategias privadas, las que tienen que afrontar el coste que supone la reproducción. De hecho, tal y como se observa en la tabla 2, los países en los que más se deja sentir el efecto negativo de la maternidad sobre el empleo femenino son aquéllos en los que las tasas de actividad femenina se han incrementado substancialmente en las dos últimas décadas, como Alemania, Francia, Luxemburgo y el Reino Unido, aunque por razones diferentes. En los casos de Francia y Alemania, se debe fundamentalmente al hecho de que las políticas familiares han favorecido el abandono del mercado laboral de las mujeres cuando se tiene un hijo, mientras que, en el caso británico, el régimen de bienestar liberal dificulta la compatibilización laboral y familiar, lo que expulsa del mercado laboral a aquellas mujeres con cargas familiares que no pueden afrontar el coste que supone pagar los servicios familiares de atención a la infancia que ofrece el mercado.

En la tabla 3 se completan los datos presentados con anterioridad añadiendo el efecto que tiene el número de hijos sobre el empleo femenino. La decisión de tener uno o más hijos dependerá de numerosos factores, entre los que se encuentran los ingresos familiares, el empleo, las políticas familiares de ayuda a la maternidad (Daly, 2000a; Korpi, 2000), así como la ayuda de la familia y del compañero (Cooke, 2001; 2003). Teniendo en cuenta que en los países del sur de Europa las políticas familiares se han desarrollado de forma muy limitada y que, por tanto, el coste económico y laboral es más elevado que en otros países, se podrá entender que la llegada del segundo y del tercer hijo tiene un efecto negativo sobre el empleo femenino, tal y como se observa

Tabla 2. Tasas de ocupación femenina según hijos, año 2000.

\begin{tabular}{lcc}
\hline & Sin hijos & Con hijos de 0 a 6 años \\
\hline Alemania & 80,8 & 53,7 \\
Austria & 79,8 & 68,2 \\
Bélgica & 76,5 & 68,9 \\
España & 56,8 & 45,3 \\
Francia & 75,0 & 59,1 \\
Grecia & 53,6 & 49,9 \\
Holanda & 81,9 & 64,0 \\
Italia & 58,4 & 46,6 \\
Luxemburgo & 74,8 & 56,0 \\
Portugal & 76,1 & 75,0 \\
Reino Unido & 72,2 & 56,4 \\
Unión Europea & 72,6 & 55,0 \\
\hline
\end{tabular}

Fuente: Eurostat, 2002. 
Tabla 3. Tasa de ocupación para mujeres de edades entre 25 y 49 años según número de hijos, 2000.

\begin{tabular}{lccccc}
\hline & $\begin{array}{c}\text { Total } \\
\text { mujeres }\end{array}$ & $\begin{array}{c}\text { Mujeres } \\
\text { sin hijos }\end{array}$ & $\begin{array}{c}\text { Mujeres } \\
\text { con un hijo } \\
\text { menor } \\
\text { de 6 años }\end{array}$ & $\begin{array}{c}\text { Mujeres } \\
\text { con dos hijos } \\
\text { menores } \\
\text { de 6 años }\end{array}$ & $\begin{array}{c}\text { Mujeres } \\
\text { con tres o más } \\
\text { hijos menores } \\
\text { de 6 años }\end{array}$ \\
\hline Alemania & 69,1 & 74,3 & 53,2 & 48,4 & 33,2 \\
Austria & 73,5 & 75,5 & 67,7 & 61,2 & 52,7 \\
Bélgica & 66,4 & 66,2 & 68,0 & 68,2 & 44,1 \\
Dinamarca & $*$ & $*$ & $*$ & $*$ & $*$ \\
España & 46,7 & 48,3 & 41,3 & 36,9 & 24,6 \\
Finlandia & $*$ & $*$ & $*$ & $*$ & $*$ \\
Francia & 68,6 & 73,2 & 62,2 & 61,4 & 34,9 \\
Grecia & 54,2 & 55,2 & 51,1 & 48,3 & 42,6 \\
Irlanda & 55,6 & 59,7 & 49,0 & 45,3 & 32,0 \\
Italia & 51,0 & 52,5 & 47,1 & 41,7 & 31,6 \\
Luxemburgo & 58,0 & 61,9 & 52,6 & 45,0 & 29,1 \\
Países Bajos & 69,8 & 73,2 & 61,9 & 57,1 & 49,0 \\
Portugal & 73,2 & 73,6 & 73,3 & 71,3 & 47,7 \\
Reino Unido & 72,1 & 78,8 & 59,8 & 59,0 & 40,4 \\
Suecia & $*$ & $*$ & $*$ & $*$ & $*$ \\
Europa 15 & 63,8 & & & & \\
\hline
\end{tabular}

* No hay datos disponibles.

Fuente: Eurostat, European Labour Force Survey, 2003.

en la tabla 3. De hecho, en Suecia, Bélgica, Francia o el Reino Unido, apenas varía la tasa de ocupación femenina entre las mujeres con un hijo y dos hijos menores de cinco años, mientras que en los casos de Alemania, Austria y España, la variación es mayor, lo que indica que en estos países la llegada del segundo hijo tiene un coste laboral mayor que en los países del norte de Europa.

En la tabla 4, se presentan los resultados relativos a la European Quality of Life Survey realizada por la European Foundation for the Improvement of the Living and Working Conditions en 2003 para 28 países europeos, en la que se pregunta a las mujeres trabajadoras con hijos por el grado de satisfacción con el cumplimiento de sus responsabilidades familiares. Los ratios por países evidencian una vez más el hecho de que en los países en los que se han desarrollado generosas políticas de compatibilización laboral y familiar, como en el caso de Finlandia o Suecia, el número de mujeres que expresa cierta insatisfacción con el cumplimiento de sus roles familiares es menor que en países como Portugal, Francia o España, donde el número de mujeres satisfechas con el cumplimiento de sus responsabilidades familiares es menor. Esto puede evidenciar, además de diferencias substanciales en las políticas de género según régimen de bienestar, también diferencias de grado en los dilemas de compa- 
Tabla 4. Dificultades que tienen las mujeres para cumplir con las responsabilidades familiares. Ratio de mujeres trabajadoras con hijos menores de 4 años del total de mujeres empleadas

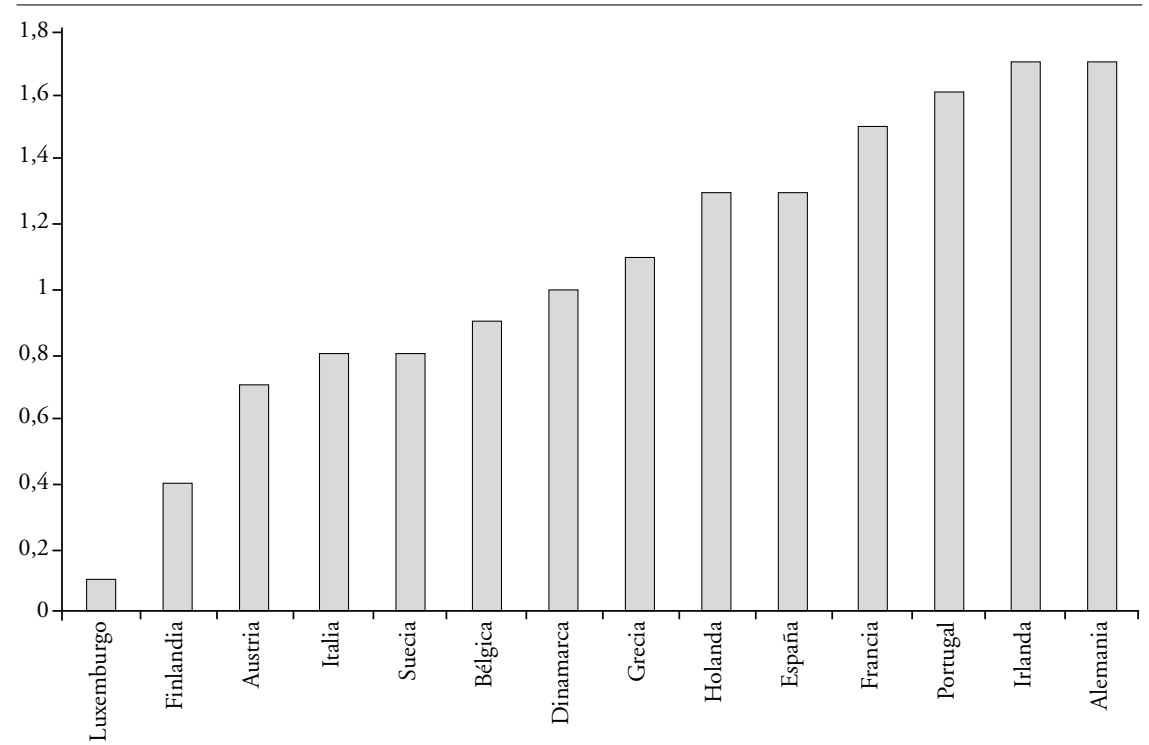

Pregunta: ¿Con qué frecuencia le ha sucedido la siguiente situación en el último año?: Respuesta B) Ha sido muy difícil para mi compatibilizar mis responsabilidades familiares varias veces a la semana o al mes, porque dedico la mayor parte del tiempo a trabajar.

Nota: el ratio de mujeres trabajadoras con hijos menores de cuatro años del total de mujeres empleadas encuestadas dice que ha tenido dificultades para realizar sus responsabilidades familiares debido al trabajo.

Fuente: European Quality of Life Survey, 2003.

tibilización laboral y familiar. En países como Alemania, donde la asunción privada de las responsabilidades familiares tiene una gran tradición en la cultura familiarista y aunque la participación laboral de la mujer sea relativamente reducida, el ratio de la tabla 4 para Alemania evidencia cierta contradicción entre los deseos y las expectativas, mientras que en un país como Finlandia, donde la cultura es menos familiarista y donde se dan elevadas tasas de ocupación laboral femenina, el empleo de la mujer con cargas familiares no parece suponer una contradicción en relación con sus expectativas familiares.

\section{Incidencia de las políticas familiares en el empleo femenino}

\section{Políticas de gasto y empleo femenino}

El marco institucional que define las políticas familiares ha sido considerado por los investigadores como un instrumento fundamental de la política social para potenciar la integración de la mujer en el mercado laboral. En el caso de los 
Gráfico 1. Tasa de actividad femenina y gastos en ayudas económicas a la familia (\% del PIB).

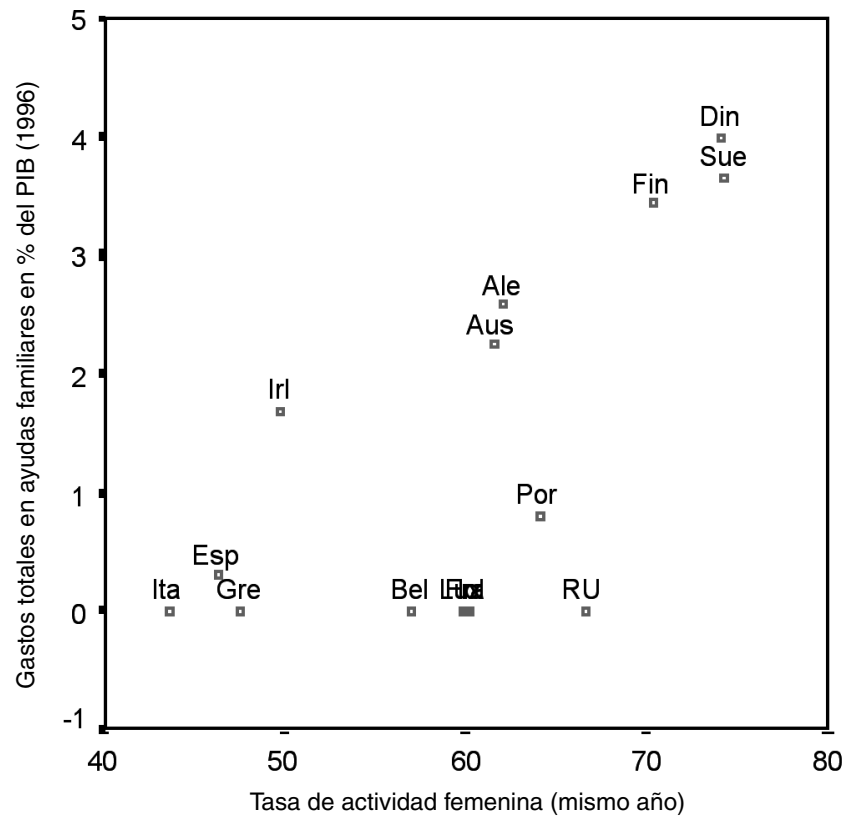

Fuente: elaboración propia a partir de Gauthier, A. H. (2003). Comparative Family Benefits Database. Versión 2. University of Calgary.

estados de bienestar del sur de Europa, la política social de atención a las familias ha girado en torno a la protección de la figura del varón sustentador, descuidando en parte las cuestiones de género, los servicios familiares y la conciliación laboral y familiar, lo que ha tenido una clara repercusión en las tasas de actividad femenina. En los gráficos de dispersión 1 y 2 se puede observar cómo los países del entorno mediterráneo (España, Italia y Grecia) forman un grupo compacto caracterizado tanto por la reducida prestación de servicios familiares, como por el reducido gasto social destinado a la familia y por las limitadas tasas de actividad femenina. Por el contrario, en países como Dinamarca y Suecia, las generosas políticas familiares desarrolladas por los estados de bienestar se corresponden con elevadas tasas de actividad femenina. Por lo tanto, la lectura de estos datos apunta a la existencia de cierto grado de asociación entre los procesos de inserción laboral femenina y el contexto institucional de los regímenes de bienestar en los que se producen.

En lo que se refiere a la asociación entre la tasa de actividad femenina y la política familiar medida a través del gasto social destinado a servicios familiares (gráfico de dispersión 3), los índices de correlación confirman la hipó- 
Gráfico 2. Tasa de actividad femenina y gastos en servicios familiares (\% del PIB).

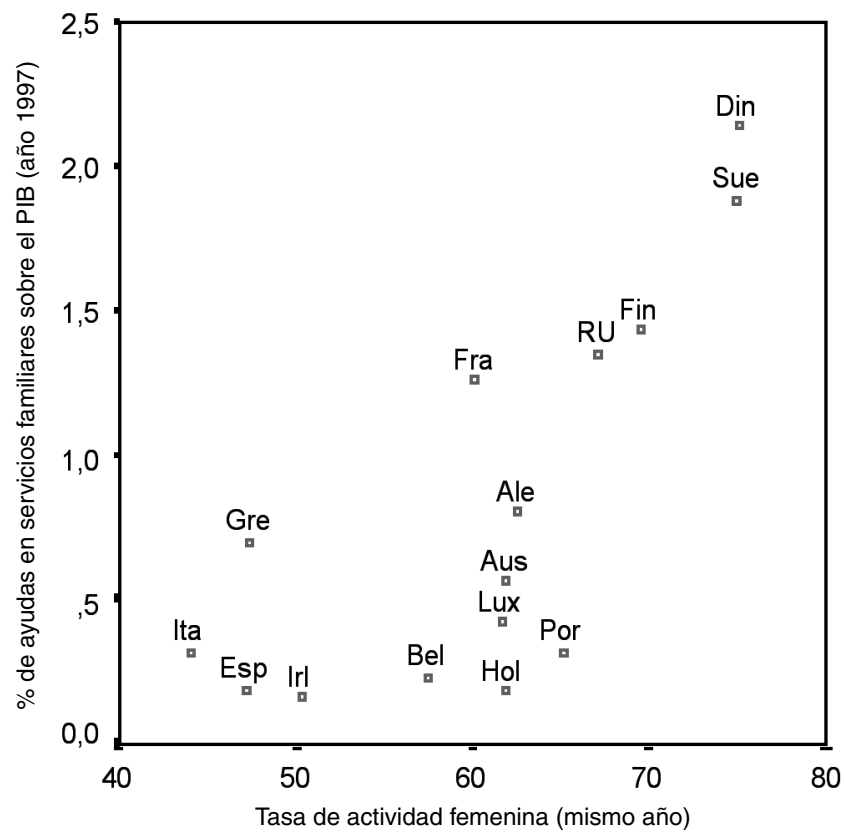

Fuente: elaboración propia a partir de Gauthier, A. H. (2003). Comparative Family Benefits Database. Versión 2. University of Calgary.

tesis de que el desarrollo de las políticas familiares ha favorecido, en cierta forma, la inserción laboral de la mujer en el conjunto de los países de la Europa de los quince. Para estos países, la tasa de actividad femenina aparece correlacionada positivamente y de forma significativa con el gasto social destinado a servicios familiares para todos los períodos de referencia. Esto significa que, para el total de los países que forman la Europa de los quince, el desarrollo de las políticas familiares en lo que se refiere a la provisión de servicios familiares públicos para atender a la infancia y a las personas dependientes, ha tenido una incidencia positiva en el empleo femenino, ya que han contribuido a potenciar la compatibilización familiar y laboral, así como el proceso de desfamiliarización a través de la integración de la mujer en el mercado laboral.

En el caso de las regiones de los países mediterráneos, no se observa ninguna asociación significativa entre la tasa de actividad femenina y el porcentaje de gastos sociales destinados a servicios familiares para los períodos analizados (gráfico 4). Estos resultados constatan que la escasa institucionalización de las políticas familiares en lo que se refiere al desarrollo de servicios familia- 
Gráfico 3. Correlación entre la tasa de actividad femenina y el \% de ayudas en servicios familiares sobre el PIB para los quince países de la Union Europea.

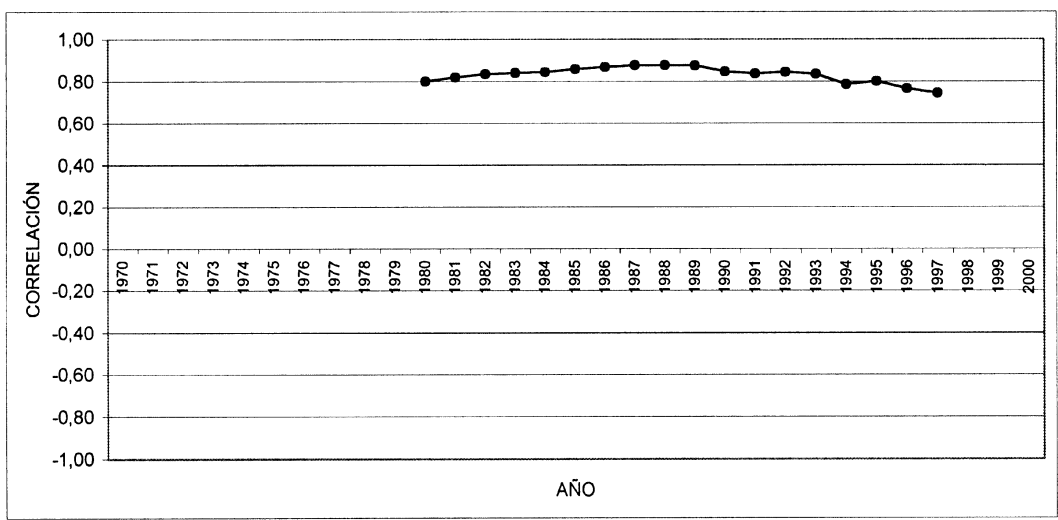

variable 13 - TASA DE ACTIVIDAD FEMENINA

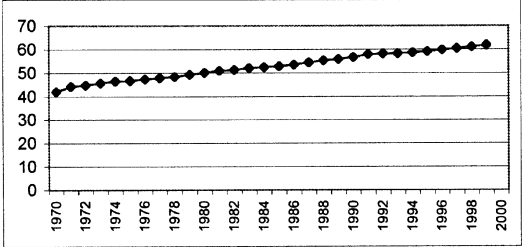

variable 19 - \% DE AYUDAS EN SERVICIOS FAMILIARES SOBRE EL PIB

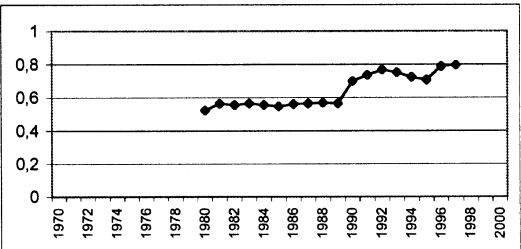

Nota y fuente: se han calculado los índices de correlación de Pearson para cada año de referencia a un nivel de significación del 0,05. Los datos referidos a la tasa de actividad femenina se han obtenido de la base de datos Regio Database, Eurostat, 2003. Los datos referentes al gasto social se han obtenido de la base de datos OECD Social Expenditure Database 1980-1999, OCDE 2000.

res de compatibilización familiar y laboral prestados por el estado y las limitadas ayudas económicas destinadas a la familia ${ }^{6}$, han podido tener una incidencia negativa en la participación laboral de la mujer con cargas familiares, ya que no han favorecido el proceso de desfamiliarización e individualización descrito por Esping Andersen (2000). En cualquier caso, estos índices calculados en esta investigación son meramente indicativos, ya que la generalidad del indicador utilizado (porcentaje de gastos sociales destinados a servicios familiares) no permite derivar interpretaciones más allá de la simple descripción del impacto real que ha tenido el gasto social en la familia sobre la tasa de acti-

6. España, Italia y Portugal son los países que menor porcentaje del PIB destinaban a gastos sociales en servicios familiares y en familia en 1998 (OCDE, 2002). 
Gráfico 4. Evolución temporal de la correlación entre tasa de actividad femenina y \% de ayudas en servicios familiares sobre el PIB, tomando como casos todas y cada una de las regiones de Grecia, Italia y España.

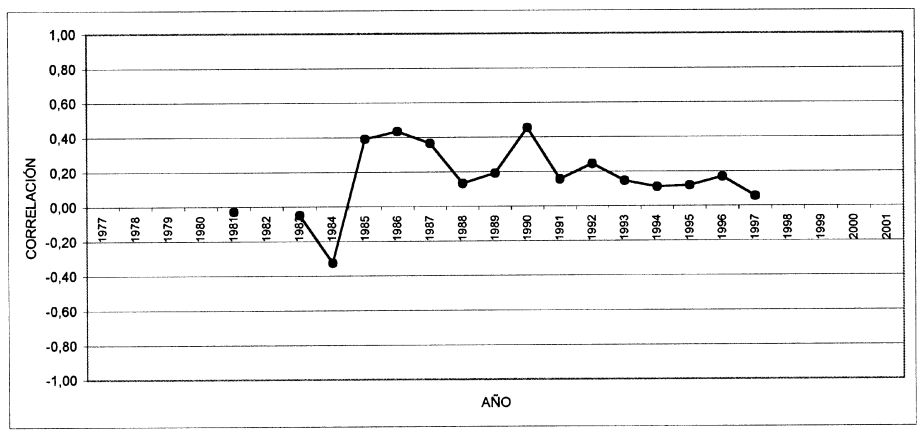

variable 13 - TASA DE ACTIVDAD FEMENINA

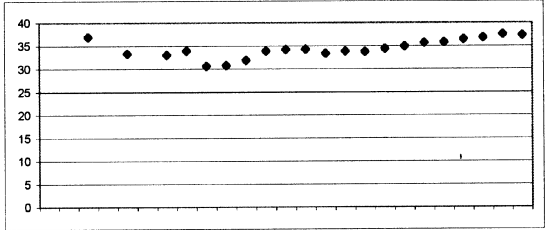

variable 19 - \% DE AYUDAS EN SERVICIOS FAMILIARES SOBRE EL P.I.B.

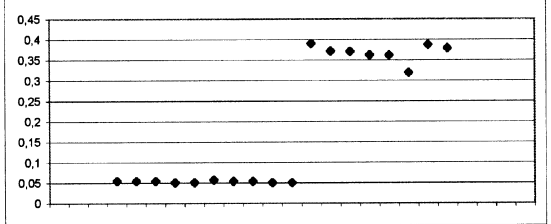

Nota y fuente: se han calculado los índices de correlación de Pearson para cada año de referencia a un nivel de significación del 0,05. Los datos referidos a la tasa de actividad femenina disponibles para todas las regiones de España, Italia y Grecia proceden de la base de datos Regio Database, Eurostat, 1980-2002, Eurostat, 2003. Los datos referentes al gasto social se han obtenido de la base de datos OECD Social Expenditure Database 1980-1999, OCDE 2000.

vidad femenina, aunque sí permite detectar diferencias significativas entre las regiones mediterráneas y el conjunto de los países de la Unión Europea. Por lo tanto, estos resultados apuntan a la tesis aquí defendida acerca de las dificultades que tienen las mujeres con cargas familiares en las regiones del sur de Europa para compatibilizar empleo y familia.

Los resultados presentados en el gráfico 4 constatan la hipótesis de que en los países del entorno mediterráneo, el escaso desarrollo institucional de las políticas familiares y las limitadas ayudas económicas destinadas a promover la conciliación laboral y familiar han dificultado la integración laboral de las mujeres, mientras que para el conjunto de los países europeos, el desarrollo de las políticas familiares ha tenido una incidencia positiva en el empleo femenino, lo cual ha favorecido la desfamiliarización y el proceso democratizador de las relaciones familiares. 


\section{Modelos de conciliación y empleo de las mujeres en los paises mediterráneos}

Las políticas de conciliación laboral y familiar parecen tener un efecto más bien directo sobre el empleo femenino, en la medida en que facilitan la externalización y la mercantilización de los servicios familiares y, por tanto, la independencia familiar de la mujer, lo cual favorece la extensión de los derechos de ciudadanía social (Boeri, Del Boca y Pissarides, 2005).

El tema de las políticas de género y, por tanto, de la conciliación laboral y familiar, ha sido recurrente en las agendas de los gobiernos desde la década de 1980. Numerosos congresos, programas e informes han enfatizado en el tema de la igualdad de hombres y mujeres ante el trabajo remunerado. Entre los mismos, se incluye, por ejemplo, la Conferencia Sueca sobre «Política para una igualdad de género en el siglo XXI», celebrada en 1999, y la Conferencia Portuguesa sobre la «Igualdad» organizada por la Comisión para la Igualdad en el Empleo y el Trabajo. En los últimos años, el tema de la familia y el trabajo ha sido prioritario en las agendas de los diferentes gobiernos en los ámbitos nacional e internacional. Destacan, entre otros eventos, la Convención de los Trabajadores con Responsabilidades Familiares de la OIT (1981), la Directiva Europea sobre «Embarazos» (1992), la Recomendación Europea sobre el «Cuidado de los Hijos» (1992), la Directiva Europea sobre las «Excedencias Parentales» (1996), la Directiva Europea sobre el «Trabajo a Tiempo Parcial»y la Resolución Europea sobre el «Balance de la participación de Hombres y Mujeres en la Familia y en la Vida Laboral» (2000). También se han producido numerosas iniciativas nacionales, tales como la aprobación del Plan Nacional de Luxemburgo sobre la «Reconciliación de la Vida Familiar y Laboral (1998-1999)», el Plan alemán sobre «Estrategias para la Compatibilización del Trabajo y la Familia» (1999) y la Campaña portuguesa sobre la «Reconciliación Laboral y Familiar» (1999). Estos informes revelan la importancia que tienen en la actualidad las políticas familiares de apoyo a las personas trabajadoras como requisito imprescindible para fomentar la democratización de las relaciones sociales, familiares y laborales.

La importancia atribuida a las políticas familiares y al cambio familiar por los efectos producidos en ámbitos como la fecundidad y el empleo de la mujer, ha llevado a numerosos investigadores a estudiar el tema de las políticas familiares a través de la definición de indicadores tales como las ayudas familiares, los permisos de maternidad, las excedencias parentales, los servicios familiares de atención a la infancia y la tercera edad, etc. en relación con la evolución de la fecundidad y el empleo femenino (Gauthier, 1996, 1999; Gornick, Meyer y Roos, 1997).

A pesar de que los estudios realizados no han sido del todo concluyentes respecto a la hipotética asociación positiva existente entre una generosa política de conciliación laboral y familiar y una mayor participación laboral de la mujer, en la mayoría de los estudios que tratan esta cuestión se deja leer entre líneas que aquellos países que han apostado por una política familiar individualizada potenciadora de la conciliación son precisamente los países en los que encon- 
tramos mayores tasas de ocupación femenina (Dinamarca, Suecia, Finlandia), lo cual indica que existe cierta conexión implícita entre las políticas de conciliación y el empleo de la mujer (Bettio y Villa, 1998; Esping Andersen, 2000; Lewis, 2004; Cousins, 2000; Fine-Davis, 2004).

El análisis comparado realizado sobre las políticas familiares de conciliación ha corroborado la existencia de diferentes modelos de conciliación laboral y familiar que se corresponden, en parte, con la tipología de regímenes de bienestar definidos en este trabajo. En este sentido, es preciso subrayar que los análisis realizados hasta el momento apuntan la existencia de tendencias convergentes para los países pertenecientes al ámbito mediterráneo, los cuales han optado mayoritariamente por un modelo de conciliación laboral y familiar escasamente desarrollado, lo que ha repercutido de forma indirecta en la integración de las mujeres con cargas familiares en el mercado laboral. En cualquier caso, es preciso destacar la existencia de ciertas diferencias entre, por ejemplo, el modelo portugués y el español.

Las familias, y concretamente las parejas con hijos dependientes, organizan el tiempo de trabajo y la división del trabajo familiar en función de la relación que mantienen con el entorno socieconómico, es decir, las parejas con hijos y familiares dependientes desarrollan estrategias familiares de carácter privado en función de los recursos públicos y privados disponibles para organizar la economía familiar y reducir costes, aunque ello revierta en un coste oculto y, por tanto, no contabilizado, como es el trabajo no pagado de la mujer dentro de los hogares familiares.

La forma en que los regímenes de bienestar distribuyen los recursos públicos destinados a la compatibilización laboral y familiar varía considerablemente entre los países europeos en función del contexto institucional de referencia. Dulk (2000) ha diferenciado tres tipos de políticas de compatibilización laboral y familiar atendiendo al marco institucional en el que se han desarrollado las políticas familiares de atención a las personas con cargas dependientes (servicios públicos de atención a la infancia, permisos de maternidad y parentales, tiempos de trabajo). Para comparar los modelos de conciliación, Bettio y Plantenga (2001) y Dulk (2000) se refieren al término de formal care provisions en referencia a la prestación de servicios familiares tales como las guarderías públicas, los permisos de maternidad y parentales, así como los tiempos de trabajo, factores todos ellos que inciden, de una u otra forma, en la situación familiar y laboral de los trabajadores con cargas familiares. En este marco de interpretación, el último trabajo de Fine-Davis y Fagnani (2004) presenta un análisis comparativo sobre los dilemas que tienen los padres trabajadores con hijos en Francia, Italia, Irlanda y Dinamarca para compatibilizar empleo y familia. Los resultados obtenidos en esta investigación resaltan el hecho de que los problemas de compatibilización laboral y familiar expresados por los ciudadanos y los modelos de familia deseados en estos países difieren en función de las políticas familiares desarrolladas por cada estado, lo cual avala la hipótesis de que el empleo femenino está directamente vinculado con las políticas familiares. 
El desarrollo de un marco institucional de apoyo a las familias con hijos se inició con la instauración de los permisos de maternidad que cada país europeo fue adaptando aplicando diferentes modalidades. En 1992, el Consejo de la Comunidad Europea adoptó la directiva referida a los permisos de maternidad (92/85/EECC), que aconsejaba la implantación de catorce semanas de permiso laboral para las madres trabajadoras, aunque no contemplaba el pago total de los salarios. Los diferentes estudios realizados a tal efecto han puesto de manifiesto que los permisos de maternidad incrementan las posibilidades de participación laboral femenina, ya que constituyen un importante respaldo institucional para ayudar a las mujeres a reconciliar las responsabilidades familiares con las laborales (Gornick, Meyer y Roos, 1997; Hantrais, 2004; Boeri, Del Boca y Pissarides, 2005).

En el gráfico 5 se presenta el grado de asociación entre la tasa de actividad femenina y el tipo de permiso de maternidad. En este gráfico se observan notables diferencias entre los diversos países de la Unión Europea. Destacan, por un lado, la mayor parte de los países de la Europa de los quince, donde el número de semanas pagadas de maternidad es aproximadamente de dieciséis $\mathrm{y}$,

Gráfico 5. Tasa de actividad femenina y número de semanas que se paga el permiso de maternidad (2000). Países de la Europa de los quince.

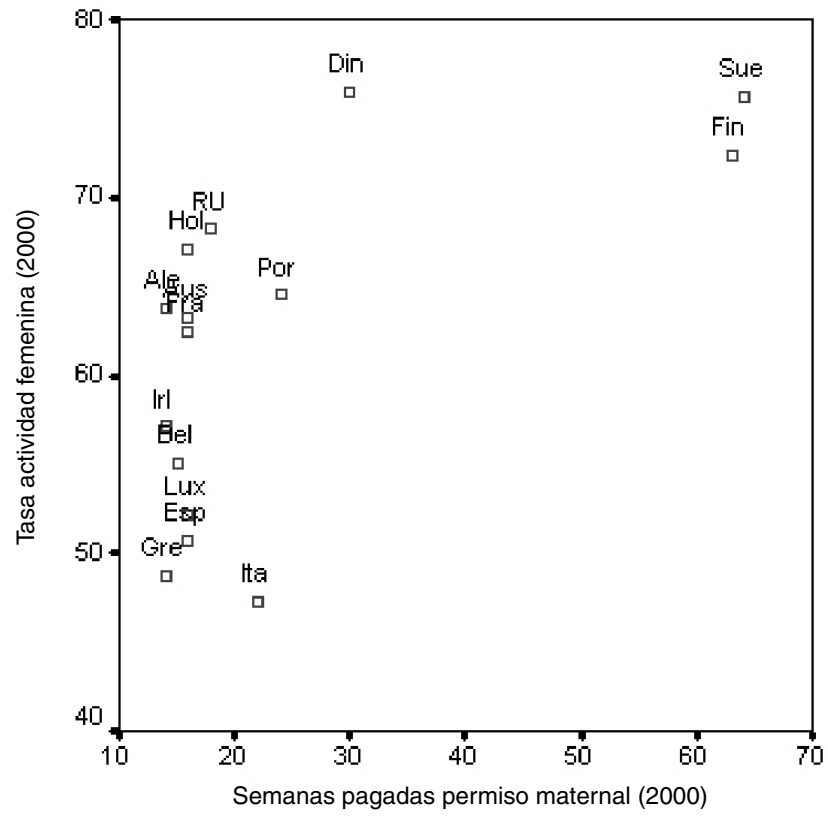

Fuente: elaboración propia a partir de Gauthier, A. H. (2003). Comparative Family Benefits Database. Versión 2. University of Calgary. 
por otro lado, destacan los países pertenecientes al régimen de bienestar socialdemócrata (Suecia y Finlandia), donde el número de semanas pagadas es superior a sesenta. En el caso de los citados países mediterráneos, este dato coincide con una reducida participación laboral de la mujer, mientras que en el Reino Unido la tasa de actividad laboral de la mujer es más elevada, a pesar de la limitada cobertura del permiso de maternidad, lo cual invita a pensar que la participación laboral de la mujer en el Reino Unido tiene relación con otros factores institucionales, tales como la estructura del mercado laboral (empleo a tiempo parcial, terciarización, etc.). El modelo de permisos de maternidad de España, Bélgica, Francia, Austria, Holanda y Portugal es muy similar, aunque con diferentes matices y, sin embargo, las tasas de actividad presentan notables diferencias. El caso más claro en el que se puede observar una asociación positiva entre los permisos de maternidad y la tasa de actividad laboral es el correspondiente a los países del régimen socialdemócrata (Dinamarca, Finlandia, Suecia), donde las elevadas tasas de actividad femenina coinciden con permisos de maternidad generosos en cuanto a la duración y a la cuantía salarial de los mismos. Por lo tanto, en el caso de estos países del norte de Europa, se puede afirmar que la regulación de los permisos de maternidad y parentales han tenido un efecto positivo sobre la actividad laboral de la mujer.

En lo que se refiere al desarrollo de los servicios familiares de atención a la infancia, existe una gran heterogeneidad en los modelos de prestación. A pesar de la gran importancia que tiene este tipo de servicios familiares, únicamente se han desarrollado plenamente en los países del norte de Europa. En Dinamarca, cada niño con más de un año tiene derecho garantizado a utilizar los servicios públicos de guarderías. En Finlandia, los padres reciben una compensación monetaria si no hay disponible una plaza pública de guardería y en Suecia todos los hijos con más de un año de madres y padres que trabajan o estudian, tienen garantizada una plaza de guardería subvencionada públicamente (Kremer, 2002). En el resto de los países de la Unión Europea, no existe una regulación de los servicios familiares de estas características. La heterogeneidad de los tipos de servicios familiares prestados en cada país dificulta la comparabilidad de los datos, por lo que, tal y como se observa en el gráfico 6, se ha seleccionado como indicador el porcentaje de niños menores de tres años en guarderías públicas. El gráfico citado evidencia la existencia de varios grupos de países. Destaca, por un lado, el grupo compacto de los países del sur de Europa (España, Grecia e Italia), en los que la reducida prestación de servicios públicos de atención a la infancia coincide con la reducida participación laboral de la mujer. De la lectura de estos datos, se podría deducir para estos países que la asociación de ambas variables indica la incidencia negativa que el limitado desarrollo institucional de los servicios destinados a las familias ha tenido sobre la actividad laboral femenina. El segundo grupo de países se correspondería con lo que se ha denominado «régimen conservador» (Austria, Holanda, Alemania y Portugal), en los que la cobertura de servicios públicos a la infancia está entre el $10 \%$ y el $20 \%$ de los niños menores de tres años, lo que se corresponde con una tasa de actividad laboral femenina media. 
Gráfico 6. Tasa de actividad femenina y \% de niños menores de tres años en guarderías públicas (2000). Países de la Europa de los quince.

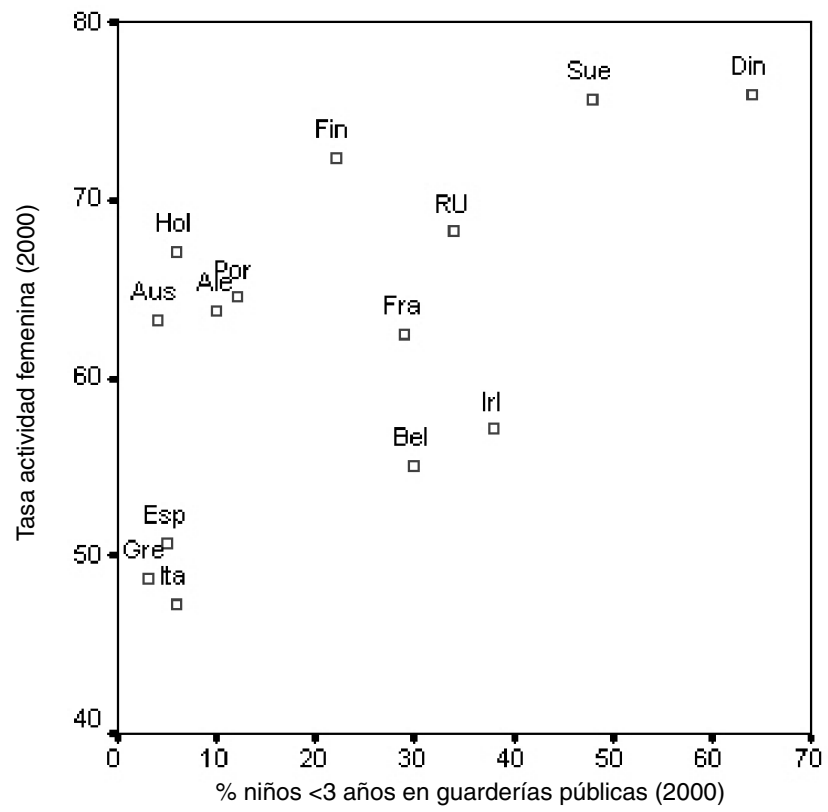

Fuente: elaboración propia a partir de Gauthier, A. H. (2003). Comparative Family Benefits Database. Versión 2. University of Calgary.

Finalmente, destacan los países socialdemócratas (Dinamarca y Suecia), en los que la elevada prestación de servicios públicos destinados a la infancia $(50 \%$ y $69 \%$, respectivamente) se corresponde con elevadas tasas de actividad y ocupación femeninas. En el Reino Unido, la cobertura pública se situaría por encima del 30\%, y la participación laboral de las mujeres es más elevada que en países como Francia y Bélgica, donde las prestaciones en servicios familiares son similares a los británicos.

Los datos presentados en este trabajo de investigación indican que los cambios experimentados en los itinerarios laborales y familiares de las mujeres en las últimas décadas se han producido de forma paralela a las transformaciones experimentadas en los modelos de conciliación laboral y familiar, así como en la propia estructura familiar. La tabla 5 refleja, de forma muy sintética, la situación laboral de las parejas con hijos menores de seis años en los diferentes países europeos. De este cuadro se puede deducir indirectamente la pertenencia de los diferentes países a distintos modelos de conciliación familiar y laboral descritos en líneas anteriores. En la tabla siguiente, se puede apreciar cómo los países del entorno mediterráneo — Grecia $(47,3 \%)$, Italia $(47,5 \%)$, España $(52,1 \%)$ - junto con 
Tabla 5. Régimen de empleo según tipo de familia (1999).

\begin{tabular}{lcccc}
\hline & \multicolumn{4}{c}{ \% de familias con hijos menores de seis años } \\
\cline { 2 - 5 } & $\begin{array}{l}\text { Hombre y mujer } \\
\text { trabajan a tiempo } \\
\text { completo }\end{array}$ & $\begin{array}{l}\text { Hombre trabaja } \\
\text { a tiempo completo } \\
\text { y mujer a tiempo parcial }\end{array}$ & $\begin{array}{l}\text { Hombre a tiempo } \\
\text { completo y mujer } \\
\text { no trabaja }\end{array}$ & $\begin{array}{l}\text { Ninguno } \\
\text { trabaja }\end{array}$ \\
\hline Alemania & 20,9 & 26,3 & 41,6 & 5,9 \\
Austria & 29,0 & 30,7 & 30,1 & 3,5 \\
Bélgica & 26,6 & 27,7 & 19,0 & 4,8 \\
España & 31,0 & 6,9 & 52,1 & 5,8 \\
Francia & 31,3 & 19,7 & 35,1 & 6,6 \\
Grecia & 41,4 & 4,2 & 47,3 & 3,4 \\
Irlanda & 29,6 & 11,4 & 41,8 & 10,9 \\
Italia & 32,6 & 9,5 & 47,5 & 6,3 \\
Luxemburgo & 26,5 & 16,6 & 51,6 & 2,4 \\
Países Bajos & 4,2 & 47,8 & 31,5 & 3,5 \\
Portugal & 60,7 & 5,9 & 25,9 & 2,4 \\
Reino Unido & 19,5 & 38,4 & 29,4 & 7,0 \\
\hline
\end{tabular}

$\%$ de mujeres que encabezan familias monoparentales

\begin{tabular}{llll}
\hline & Tiempo completo & Tiempo parcial & No trabaja \\
\hline Alemania & 24,0 & 23,9 & 52,1 \\
Austria & 43,5 & 31,2 & 25,2 \\
Bélgica & 22,1 & 24,4 & 53,5 \\
España & 50,2 & 11,4 & 38,5 \\
Francia & 34,9 & 14,1 & 51,0 \\
Grecia & 50,9 & 8,4 & 40,7 \\
Irlanda & 15,5 & 18,6 & 65,9 \\
Italia & 58,7 & 10,8 & 30,5 \\
Luxemburgo & 52,3 & 19,7 & 27,9 \\
Países Bajos & 6,0 & 31,5 & 62,5 \\
Portugal & 75,7 & 5,7 & 18,6 \\
Reino Unido & 12,5 & 21,7 & 65,8 \\
\hline
\end{tabular}

Fuente: OECD Employment Outlook, junio 2001.

Cálculos realizados a partir de la encuesta Employment Options of the Future (EOF). 
Alemania (41,6\%) y Luxemburgo (51,6\%), tienen la mayor proporción de parejas con un solo sustentador (el hombre trabaja a tiempo completo y la mujer no trabaja), aunque se ha producido un descenso relativo en el número de parejas con un sólo sustentador en la última década. En definitiva, estos datos parecen indicar que, en general, en España, Italia y Grecia la práctica inexistencia de un modelo de conciliación familiar y laboral ha repercutido negativamente en la situación laboral de las mujeres con hijos menores de seis años. De hecho, muchas de estas mujeres, pertenecientes fundamentalmente a los estratos más humildes, se han visto abocadas a renunciar al trabajo ante la carencia generalizada de alternativas institucionales de apoyo a la familia y el elevado coste de las mismas en el mercado. Muy diferente es el caso de las familias monoparentales encabezas por mujeres residentes en países como España, Italia o Grecia, donde es precisamente la carencia de una política familiar de ayuda a estas familias lo que explica que estas mujeres, ante la falta de un varón sustentador, hayan optado mayoritariamente por trabajar para sostener la economía familiar. Es de suponer, en concordancia con lo expuesto anteriormente, que estas mujeres acudan a la ayuda familiar (concretamente, los abuelos, los parientes o los vecinos y amigos) para poder conciliar la vida familiar y laboral. Así se explica que España, Italia o Grecia registren elevados porcentajes de mujeres ocupadas que encabezan hogares monoparentales, superando incluso las proporciones de países como Francia, Bélgica, Países Bajos o el Reino Unido. Es aún más significativo el reducido porcentaje de mujeres que encabezan un hogar monoparental y que no realizan ninguna actividad remunerada en los países del sur de Europa en comparación con los Países Bajos y el Reino Unido.

Al hilo de esta argumentación, resulta muy apropiado reflexionar sobre la información contenida en la encuesta Employment Options of the Future (EOF), realizada por la Unión Europea en 1998, en la que se recogen las preferencias de las parejas con hijos menores de seis años respecto a las diferentes modalidades y estrategias de empleo para los miembros de la pareja. En lo que se refiere a los países mediterráneos, destaca el hecho de que un porcentaje muy elevado de los padres (el 59,7\% en España, el 50,4\% en Italia, el 65,6\% en Grecia y el 84,4\% en Portugal) expresan que desearían abandonar el modelo familiar formado por un solo sustentador en favor del modelo más igualitario de pareja en el que los dos miembros trabajasen a tiempo completo. Los resultados son similares a los obtenidos por Fine-Davis y Faganani (2004) en la encuesta realizada para Italia, ya que los ciudadanos entrevistados expresan la contradicción inherente entre el deseo de trabajar los dos miembros de la pareja y las dificultades que encuentran para compatibilizar empleo y familia. Esto es sintomático de que algo está empezando a cambiar en los países mediterráneos, a pesar del desfavorable contexto institucional existente hasta el momento para compatibilizar la vida laboral y familiar. El gobierno español ha aprobado recientemente el Plan integral «Concilia» para mejorar las condiciones actuales de la conciliación laboral y familiar de los trabajadores de la Administración Pública (BOE 16 de diciembre de 2005).

Por otro lado, también destaca, en términos comparativos, el reducido porcentaje de padres españoles $(11,6 \%)$ y griegos $(10,6 \%)$ que desearían un mode- 
lo laboral intermedio (varón trabajando a tiempo completo y mujer a tiempo parcial), si lo comparamos con los padres holandeses, quienes, en un $69,9 \%$, consideran que es una opción laboral y familiar viable como estrategia de compatibilización. Esto es debido a que, en la mayoría de los países del sur de Europa, la oferta de trabajo a tiempo parcial es una opción relativamente poco desarrollada y poco atractiva para los padres, mientras que, en el caso holandés, el trabajo a tiempo parcial es una opción que ofrece el mercado laboral muy demandada por madres y padres, tal y como se puede observar en la tabla 5 .

Bien es cierto que las estrategias laborales adoptadas por las diferentes familias no sólo dependen de las políticas familiares de conciliación, sino de numerosos factores entre los que se encuentra la situación económica de la familia. En este sentido, la encuesta mencionada anteriormente (EOF) señala de forma latente que, en muchas familias con hijos menores de seis años, los ingresos del segundo sustentador son imprescindibles para mantener la economía familiar, mientras que, en familias con una situación económica desahogada, los padres no tendrían inconveniente en reducir las horas de trabajo. Esto indica que las políticas de conciliación laboral y familiar son una opción deseada no sólo para potenciar la independencia económica de las mujeres, sino también para favorecer la equiparación de las rentas familiares más reducidas, ya que, en muchas familias del sur de Europa, el trabajo de la mujer es necesario para completar las rentas de la economía familiar. En muchas familias, el trabajo es incompatible con las responsabilidades familiares, debido al elevado coste de los servicios, fundamentalmente para las mujeres de bajo estatus social, por lo que en muchos casos estas familias tienen que resolver el dilema de la compatibilización laboral y familiar acudiendo a estrategias privadas de conciliación.

En síntesis, se puede concluir este apartado subrayando que aquellos países que han apostado decididamente por una política de conciliación laboral y familiar son los que mayores niveles han conseguido de externalización de los servicios familiares, lo cual ha potenciado el empleo y la independencia económica de las mujeres como en el caso de Suecia, Dinamarca o Finlandia. Por el contrario, en los países mediterráneos, en general se considera que el cuidado de los menores es un asunto privado que tienen que resolver las familias, lo que ha dificultado considerablemente la desfamiliarización y la independencia de las mujeres.

\section{Conclusiones}

En este trabajo, se ha tratado de vincular las características del régimen de bienestar mediterráneo en materia de política familiar con la reducida participación laboral femenina en países como España e Italia.

Si bien la literatura científica comparada sobre los estados de bienestar apunta hacia la idiosincrasia característica del régimen de bienestar y familiar de los países del sur de Europa, en este artículo se ha tratado de avanzar en la fundamentación teórica de esta línea de investigación señalando algunas de las peculiaridades que definen al modelo de bienestar mediterráneo, tales como 
la reducida participación laboral de la mujer, el limitado marco institucional de apoyo a las madres con cargas familiares y la permanencia de la solidaridad y la dependencia familiar (familiarismo).

Los análisis empíricos realizados para los países del sur de Europa (España, Grecia e Italia) ponen de manifiesto la existencia de algún tipo de vinculación entre el marco institucional del estado de bienestar, caracterizado por un limitado desarrollo de las políticas familiares y las estrategias laborales y familiares adoptadas por las mujeres de estos países. Si bien no se puede afirmar con rotundidad que las políticas familiares sean un elemento determinante por sí mismas del empleo femenino, para el caso de los países aquí estudiados, los cálculos realizados evidencian que, tanto las políticas familiares de gasto social como las políticas de conciliación laboral y familiar, tienen diferente incidencia en el empleo femenino según el régimen de bienestar considerado. En el caso de los países del sur de Europa (España, Italia y Grecia), los limitados gastos sociales en familia y la rudimentaria política de conciliación laboral y familiar explican en parte las dificultades que expresan las mujeres de estos países para compatibilizar empleo y familia y, por tanto, la reducida participación laboral de las mujeres con cargas familiares. Sin embargo, para el caso de los países del norte de Europa, tales como Suecia, Finlandia y Dinamarca, las generosas políticas de género y familiares desarrolladas por los estados de bienestar parecen haber tenido una incidencia positiva sobre el empleo femenino, tal y como avalan los análisis presentados en este trabajo.

En consecuencia, el trabajo aquí presentado apoya la tesis de que el marco institucional diseñado desde los estados de bienestar en materia familiar tiene algún tipo de incidencia sobre las estrategias laborales y familiares adoptadas por los ciudadanos y, por lo tanto, en el grado en que se produce la democratización de los derechos de ciudadanía social a través de la incorporación de las mujeres al mercado laboral. Sin embargo, no debemos olvidar que hay otros factores de gran relevancia a la hora de explicar este fenómeno, tales como la incidencia y la reproducción de las pautas culturales, en los que hay que seguir profundizando desde ópticas empíricas más cualitativas.

\section{Bibliografía}

AlbA, A. (2000). La riqueza de las familias. Mujer y mercado laboral en la España democrática. Barcelona: Ariel.

Alberdi, I. (1999). La nueva familia española. Madrid: Taurus.

Bahle, T.; Pfenning, A. (2000). Families and Family Policies in Europe. Comparative perspectives. Nueva York: Peter Lang.

BeCK, U.; BeCK-GERNSHEIM, E. (2002). Individualization. Institucionalized individualism and its social and political consequences. Londres: Sage Publication.

Benigno, F. (1989). «Famiglia mediterranea e modelli anglosassoni». Meridiana, 6, p. 29-61.

Bettio, F.; Plantenga, J. (2001). Comparing Care Regimes in Europe. Siena/Utrecht: The Netherlands. 
BETTIO, F.; ViLLA. P. (1993). «Structure familiarie mercati del lavoro nei paesi sviluppati. L'emergere di un percorso mediterraneo per l'integrazione delle donne nel mercato lavoro». Economia e Lavoro, vol. XXVII, 29, p. 3-30.

- (1998). "A mediterranean pespective on the breakdown of the relationship between participation and fertility». Cambridge Journal of Economics, vol. 22, 2, p. 137-171.

BIMBI, F. (1999). «The family paradigm in the Italian Welfare State». Southern European Society and Politics, vol. 4, 2, p. 72-88.

BlancheT, D.; PENNEC, S. (1993). «A Simple Model for Interpreting Cross-tabulations of Family Size and Women's Labor Force Participation». European Journal of Population, 9, p. 121-142.

Boeri, T.; Del Boca, D.; Pissarides, C. (2005). Women at work: An economic Perspective. Oxford: Oxford University Press.

BRADSHAW, J. y otros (1993). «A comparative study of child support in fifteen countries». Journal of European Social Policy, 3 (4), p. 255-571.

CASTLES, F. (1993). Families of nation patterns of public policy in western democracies. Darthmouth: Aldershot.

- (1995). «Welfare State development in Southern Europe». West European Politics, 18 (2), p. 291-213.

- (1998). Comparative public policy. Patterns of post-war transformation. Cheltenham: Edward Elgar.

Cooke, L. P. (2001). «Balancing Fertility and Employment in Post-Industrial Economies: A comparision of the Dual-Earner Effect on Family Size in Nine Countries». IRISS Working Paper, series no 2001-5.

- (2003). «The south revisited: The division o labor and family outcomes in Italy and Spain» IRISS Working Paper, series no 2003-12, Luxemburgo.

Cousins, C. (2000). «Women and Employment in Southern Europe The implications of Recent Policy and Labour Market Directions». South European Society and Politics, (5), 1, 2000, p. 97-121.

Daly, M. (2000a). The Gender Division of Welfare. Cambridge: Cambridge University Press.

- (2000b). «A Fine Balance: Women's Labor Market Participation in International Comparision». En: SCHARPF, F.; SCHMIDT, V. (eds.). Welfare and Work in the Open Economy: Diverse Responsen to Common Challenges. Nueva York: Oxford University Press, p. 467-510.

Daly, M.; RAKe, K. (2003). Gender and Welfare State. Londres: Blackwell.

DEL BoCA, D. (2002). «Low fertility and labour force participation of Italian women evidence an interpretation». Occasional Papers. Francia: OECD.

Del Boca, D.; Locatelli, M. (2002). «Fertility and women's work status». En: Del Boca, D.; Symeonidou, H.; Le CaCheux, J. The rationale of motherhood choices: influence of employment conditions and of Public Policies. Luxembourg Income Study Working Paper, State of the ART, p. 149-169.

Dulk, L. Den, VAN DoOrne, Huiskes; SCHIPPER, S J. (eds.) (2000). Work-Family Arrangements in Europe. Amsterdam: Thela Thesis.

DumON, W. (1987). «La politique familiale en Europa occidentale: une réflexion sociologique». L'Année Sociologique, vol. 37, p. 291-311.

EbBingHAUS, B. (1998). «European Labor Relations and Welfare States: A Comparative Analysis of their "Elective Affinities"». International Conference of Europeanists. Baltimore, 26-28 de febrero. 
EKERT-JAFFÉ, O. (1986). «Effect et limites des aides financiéres aus familles: Une expérience et un modléle». Population, 41(2), p. 327-348.

EngelHardT, H.; KÖGEL, T.; PrSKaWeTZ, A. (2003). Fertility and women's employment reconsidered: a macro-level time series for developed countries. Max Planck Institute for Demographic Resesarch.

Ermisch, J. (1989). "Purchased Child Care, Optimal Family Size and Mother's Employment: Theory and Economic Analysis». Journal of Population Economics, 2, p. 79-102.

EsPING ANDERSEN, G. (1993). Los tres mundos del estado de bienestar. Valencia: Edicions Alfons El Magnànim.

- (2000). Fundamentos sociales de las economías postindustriales. Barcelona: Ariel. EUROPEAN QuALITY OF LIFE SURVEY (2003). Families, work and social networks. Dublín: European Foundation for the Improvement of Living and Working Conditions. FERNÁNDEZ, R.; FogLI, A. (2005). Culture: An Empirical Investigation of Beliefs, Work and Fertility. Versión NBER/CEPR WP.

FERRERA, M. (1993). Modelli di solidarieta politica e riforme sociale nelle democrazie. Bolonia: II Mulino.

- (1996). «The Southern Model of Welfare in Social Euorpe». Journal of European Social Policy, 1, p. 17-37.

Fine Davis, M.; Fagnani, J.; Giovanini, D.; Hojgard, L.; Clarke, H. (2004). Fathers and Mothers Dilemmas of the Work-Life Balance. A comparative Study in Four European Countries. Social Indicadors Research Series, volumen 21. Londres: Kluwer Springer.

FLAQUER, L. (2000). Is there a Southern Euroepan model of family policy? En: BHALE, T.; Pfenning, A. (eds.). Famillies and Family Policies in Europe. Comparative perspectives. Oxford: Peter Lang.

- (2002). «Political Intervention and Family Policy in Europe and the USA Family Policy and the Maintenance of the traditional Family in Spain». En: CARLING, A.; DunCAN, S.; EDWARS, R. (eds.). Analysing Families Morality and Rationality in Pôlicy and Practise. Londres: Routledge, p. 84-92.

GAUTHIER, A. H. (1996). «The measured and unmeasured effects of welfare benefits on families: Implications for Europe's demographic trends». En: ColEMAN, D. (ed.). Europe's Population in the 1990's. Oxford: Oxford University Press, p. 297-331.

- (1999). "The sources and methods of comparative family policy research". Comparative Social Research, 18, p. 3-51.

- (2003). Comparative Family Benefits Database. Versión 2. University of Calgari. GINER, S. (1995). «La modernización de la Europa meridional». En: SARASA, S.; MORENO, L. (eds.). El estado de bienestar en la Europa del sur. Madrid: CSIC, p. 9-59.

GornicK, J.; MEYER M.; Ross, K. (1997). «Supporting the Employment of Mothers: Policy Variation across Fourteen Welfare States». Journal of Social Policy (7), p. 45-70.

GougH, I. (1996). «Social Assistance in Southern Europe». South European Society and Politics, vol. 1 (1), p. 1-23.

Guillen A. (2002). «Protección social, género y ciudadanía: el estado de bienestar español en el marco de la Unión Europea». En: Flaquer, L (ed.). Políticas familiares en la Unión Europea. Barcelona: Institut de Ciències Polítiques i Socials. Hantrais, L. (2004). Family Policy Matters. Policy Press.

Hantrais, L.; Letablier, M. (1996). Families and Family Policies in Europe. Londres: Longman. 
Hoem, B. (2000). «Entry into motherhood in Sweden: the influence of economic factors on the rise and fall in fertility, 1986-1997». Demographic Research. En línea: $<$ www.demographic-research.org/volumes/vol2/4>.

IgLeSIAS DE UsSell y MeIL, G. (2001). La politica familiar en España. Barcelona: Ariel.

JuRADO, T.; NALDINI, M. (1996). «Is the south so different?. Italian and Spanish families in comparative perspective». South European Society and Politicis, 1 (2), p. 42-66.

Kamerman, S.; KAHN, A. (1978). Goverment and families in Fourteen Countries. Nueva York, Columbia: University Press.

- (eds.) (1991). Childcare, parental leave: Policy innovation in Europe. Westport: Auburn House, p. 201-224.

KING. M. (2002). Strong families o patriarchal economies. Southern European labor markets and welfare in comparative perspective, Mediterranean Programme Series. Robert Schuman Centre for Advaced Studies. European University Institute.

KNIJN T.; AAFKE, K. (2004). Solidarity between the sexes and the generations Tranformations in Europe. Chetenham: Edward Elgar Publishing, p. 66-88.

KöGEL, T. (2003). Did the association between fertility and female employment within $O E C D$ countries really change its sign? Max Planck Institute for Demographic Research Working Paper, p. 2001-34.

KORPI, W. (2000). «Faces of Inequality Gender, Class and Patterns of Inequalities in Different Types of Welfare States». Social Politics, 7, p. 127-191.

KREMER, M. (2002). Welfare states and the moral predicament of caring. A european comparision. Comunicación presentada en la conferencia Social Values, Social Policies, European Social Policy Research Network, Tilburg, 29-31 de agosto de 2002.

KRIEGER, H. (2004). No future without children demographic developments in Europe. European Foundation for the Improvement of Living and Working Conditions, EU Ministerial Conference Family means Future-Joint Family Policy Thrust in the European Union

LEIBFRIED, S. (1993). «Towards a European welfare state?». En: JONES, C. (ed.). New Perspectives on the Welfare State in Europe. Londres y Nueva York: Routledge, p. 133-156.

LesthaEgue, R.; MeEKERS, D. (1986). «Value changes and the dimensions of familis in the European Community». European Journal of Population, 2, p. 225-268.

LEWIS, J. (1992). «Gender and development of welfare regimes». Journal of European Social Policy, 2 (3), p. 159-173.

LEWIS, L. (2004). «Emerging gender regimes and policies for gender equity in a wider Europe». Journal of Social Policy, 33, 3, p. 373-394.

LeWIS, L.; OsTNER, I. (1994). Gender and the Evolution of European Social Policies. Universität Bremen. Centre for Social Policy Research, ZeS-Arbeitspapier, no 4/94, $63 \mathrm{p}$.

López Blasco, A. (2006). «La familia como respuesta a las demandas de individualización: ambivalencias y contradicciones». Papers. Revista de Sociologia, 79, p. 263-284.

MADRUGA, I. (1996). «El papel del Estado como garante de la compatibilidad entre el rol familiar y el laboral. Análisis de las políticas familiares de los países de la Unión Europea». En: VV.AA. Dilemas del estado de bienestar. Madrid: Fundación Argentaria, Visor.

MCDONALD, P. (2001). «The toolbox of public policies to impact on fertility, a global view». En: Begavos, C.; Martin, C. Low Fertility, families an public policies. Annual Seminar, 15-16 de septiembre de 2000. European Observatory. 
Meil Landwelin, G. (1995). «Presente y futuro de la política familiar en España». Revista Española de Investigaciones Sociológicas, p. 67-90.

Messu, M. (2000). «Solidarism and familialism: the influence of ideological conceptions on the formation of French social protection». Comparing Social Welfare Systems in Nordic Europe and France. Copenhagen Conference, vol. 4. Collection MIRE, p. 113-126.

MEulders, F.; O’DORCHAI, S. (2002). «Welfare State Comparisions and Motherhood». En: Del Boca, D.; Symeonidou, H.; Le CaCheux, J. The rationale of motherhood choices: influence of employment conditions and of Public Policies. Luxemburgo Income Study Working Paper. State of the ART, p. 46-84.

MingIONE, E. (1995). «Labour market segmentation and informal work in southern Europe». European Urban and Regional Studies, 2 (2), p. 121-143.

MorenO, L. (1996). "Southern Welfare States in Transition Crisis, What Crisis?. Issues for Discussion». Paper submitted at the Conference on Social Research and Social Polciy in Southern Europe. 13 y 14 de septiembre. Universidad de Atenas.

- (2002). «Estados de bienestar y mallas de seguridad». Unidad de Políticas Comparadas (CSIC). Documento de Trabajo 02-03, 2002B32, p. 1-32.

NaldinI, M. (2003). The Family in the Mediterranean Welfare States. Londres: Frank Cass.

NEYER, G. (2003). Family policies an low fertility in Western Europe. Max Planck Institute for Demographic Research.

O'ConNor, J. (1996). «From Women in the Welfare State to Gendering Welfare State Regimens». Current Sociology, 44(2), p. 1-124.

OECD (1999). «Recent labour market development and prospects». OECD Employment Outlook. París.

- (2001a). «Balancing work and family life: helping parents into paid employment». OECD Employment Outlook. París.

- (2001b). Employment Outlook. París.

- (2002). Babies and Bosses. Reconciling work and family life. París.

OrLofF, A. (2001). «Gender equality, women's employment Cross-National Patterns and Politics». Paper presented in the meetinf of International Sociological Association. Septiembre.

Papadopoulos, T. (1998). "Greek Family Policy from a Comparative Perspective». En: Drew, E.; EMEReK, R.; MAhon, E. (eds.). Women, Work and the Family in Europe. Londres y Nueva York: Routledge, p. 47-57.

Rhodes, M. (1997). «Southern European Welfare States Identity, Problems and Prospects for Reform». En: RHODES, M. (ed.). Southern European Welfare States Between Crisis and Reform. Londres: Frank Cass, p. 1-22.

RousSEL, L. (1992). «La famille en Europe Occidentale. Divergences et convergences». Population, 47, p. 133-152.

RuberY, J.; SMith, M.; FAGAN, C. (1999). Women's employment in Europe. Trends and Prospects. Londres: Routledge.

SAINSBURY, D. (1999). Gender and Welfare State Regimes. Oxford: Oxford University Press.

Saraceno, C. (1994). «The Ambivalent Familism of the Italian Welfare State». Social Politics, 1, p. 60-82.

- (2003). Mutamenti della famiglia e politiche sociale in Italia. Bolonia: Il Mulino.

SJÖBERG, O. (2004). «The role of family policy institutions in explaning gender-role attitudes a comparative multilevel analysis of thirteen industrialized countries». Journal of European Social Policy, vol. 14 (2), p. 107-123. 
Titmuss, R. M. (1958). Essay on the Welfare State. Londres: Allen and Unwin. Toвío, C. (2001). «Working and Mothering: Women's Strategies in Spain». European Societies, 3, 3, p. 339-372.

TORres, A. (2004). Homens e Mulheres entre Familia e Trabalho. Lisboa: CITE, Comissao para a Igualdade no Trabalho e no Emprego, Estudios no 1. (2004). Vida Conjugal e Trabalho. Lisboa: Celta Editora.

TRIFILETTI, R. (1999). "Southern European welfare regimes and the worsening position of women». Journal of European Social Policy, vol. 9 (1), p. 49-64.

UunK, W.; Kalmijn, M.; MufFEls, R. (2003). «The impact of children on women's labor supply in Europe. A reassessment of the Role of Institutions». EPAG Working Papers, $\mathrm{n}^{\circ}$ 2003-39. European Panel Analysis Group.

WALBY, S. (2001). From gendered welfare state to gender regimes National differences, covergence, or restructuring? Comunicación presentada en Gender and Society Group. Universidad de Estocolmo.

ZanatTA, A. (1999). «Family Policy in Mediterranean Countries», en Foundation for the Child and the Family, Family Europe, $21^{\text {st }}$ century. Visions and Institutions. Atenas: Nez Synora.

Zimmerman, S. (1988). Understanding Family Policy. Theoretical Approaches. Londres: Sage.

ZuanNA, D. (2001). «The banquet of Aeolus A familistic interpretation of Italy's lowest low fertility». Demographic Research, vol. 4. Consultado en: <www.demographic-research.org>. 